\title{
Conflictos socioambientales $y$ alternativas de la sociedad civil
}

Mariana Alejandra García Rivas

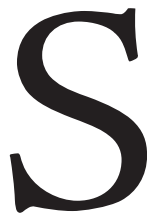

amir Amin (2001) señala que el objetivo del capital es controlar y expandir el mercado, saquear los recursos y sobreexplotar la mano de obra en la periferia. Rosa Luxemburgo identifica «un carácter dual de la acumulación de capital... [un proceso que] se realiza entre el capital y las formas de producción no capitalistas» (Harvey, 2004) relacionado con el engaño, la violencia, la opresión y la rapiña; lo que Marx (1980) llama acumulación originaria basada en el despojo por medio de la violencia. Estas visiones son retomadas y pulidas por David Harvey cuando habla de acumulación por desposesión para explicar las dinámicas de acumulación en las que se mueve el «nuevo imperialismo», en respuesta a la crisis capitalista de los años setenta (Tetreault, Ochoa y Hernández, 2012).

En la reconfiguración económico-política de la posguerra, ante los procesos de industrialización que cobraban dimensiones inéditas, comienza «a expresarse un conjunto de preocupaciones sociales por la destrucción del medio ambiente [...]; surgían así los primeros elementos de lo que después constituiría una teoría política verde que tendría repercusiones en los más diversos 
ámbitos [...]; al ser estos temas del conocimiento público empezó a nacer un campo de fuerza que ha influido múltiples espacios de lo social» (Gutiérrez y González, 2010). En los últimos años han emergido diversos movimientos sociales que reclaman la reposición de los daños sociales, económicos, políticos y ambientales generados por el capitalismo.

Este marco, en el que estamos anclados, dibuja líneas que permiten explicar la importancia de la creación y difusión de libros como Conflictos socioambientales y alternativas de la sociedad civil. En gran parte de su composición, los autores manifiestan algunas de las muchas historias de luchas y problemas ambientales que viven comunidades enteras en México gracias a las externalidades y a la acumulación por desposesión que genera el capital. Como bien lo señalan sus coordinadores, refleja el camino espinado y en ocasiones desolado que enfrentan los diversos movimientos socioambientales, que no son otra cosa que «luchas anticapitalistas que han surgido para resistir "la acumulación por desposesión”» (Tetreault, Ochoa y Hernández, 2012) que han respaldado las políticas y gobiernos neoliberales de las últimas tres décadas.

Los conflictos ambientales no son recientes, pero en los últimos años se han incrementado. En las páginas de este libro podemos encontrar estudios de caso de diversas comunidades del estado de Jalisco, donde las luchas incansables van por la defensa de los recursos naturales, identidad, medio ambiente, territorio - como un lugar proxémico lleno de simbolismos identitarios- y de la historia que encarna la tierra de todas las generaciones que han construido el territorio. Estos conflictos han generado movilizaciones socioambientales que buscan proteger o recuperar sus entornos. Joan Martínez Alier define estas movilizaciones como «ecologismo de los pobres», con objetivos que se definen en términos de las necesidades ecológicas para la vida, lo que implica resguardar los recursos naturales fuera del sistema capitalista (Tetreault, Ochoa y Hernández, 2012).

Estos casos nos invitan a reflexionar en las problemáticas que encierra la acción y participación comunitaria, sus estrategias y alternativas para dar respuesta a estos conflictos generados por la expansión del capital y la ex- 
plotación desmedida de los recursos naturales. Problemáticas que giran en torno a la construcción de presas hidroeléctricas, contaminación del agua, deforestación, monocultivos de árboles, conflictos de minería, extracción de combustibles fósiles y conflictos por la ubicación de residuos. Los puntos de convergencia que los reúne van más allá de la historia, la identidad y el territorio que comparten; están ligados al compartir un «atropello a la vida» al realizarse «obras» $y$ «acciones» para el progreso y desarrollo. Un desarrollo y progreso que las comunidades no entienden: ¿para quién o para qué?, cuando a costa de ello hay que destruir ecosistemas y dinámicas de vida.

La resistencia de estos movimientos socioambientales está acompañada por redes a nivel local y global que nutren el camino. Parafraseando a Gardel $:^{1}$ «la lucha es cruel y es mucha, pero [uno] lucha y se desangra, por la fe que lo empecina [...] en su afán...» de defender lo que se cree propio. Las estrategias de la acción colectiva son importantes para generar flujos de redignificación, donde la diversidad se hace presente y se forjan o se rompen lazos de confian$z a$; los que consiguen sobrellevar la heterogeneidad establecen objetivos afines por medio de la tregua.

En estos estudios de caso se describe un Estado velador de los intereses del capital, sea local o internacional, donde los gobiernos son corruptos y los actores afectados se sienten traicionados y abandonados por quien décadas atrás era su protector.

El libro no se queda en la descripción y el análisis de los casos, también explica la organización, cohesión y conflictos de los diferentes movimientos socioambientales. María Fernanda Paz analiza a la Asamblea Nacional de Afectados Ambientales (ANAA) y elabora un mapeo y una clasificación a nivel nacional, según la problemática que los aqueja, de los movimientos socioambientales. Considera que los conflictos y los movimientos representan una oportunidad para una construcción sociopolítica diferente que brinde

/1/ Fragmento del tango Uno, letra de Enrique Santos Discépolo (1943) y música de Mariano Mores. 
respuestas contrahegemónicas. Enfatiza que lo económico (procesos de desarrollo, expansión del capital y privatización de bienes naturales) y lo político (imposición, corrupción, luchas de poder) provocan la afectación ambiental.

En la misma línea, Heliodoro Ochoa, en el capítulo «Mapeo de conflictos ambientales y alternativas en Jalisco, para una metodología», sistematiza y analiza los conflictos de una manera más eficaz. Dicha metodología busca contribuir al «reconocimiento de la diversidad socio ambiental, la dinámica de los conflictos, así como la conformación de redes sociales que pugnan por la defensa del medio ambiente, su territorio, derechos y formas de vida» (Ochoa, 2012). El autor cree imperante un mapeo «que permita ubicar, caracterizar y contextualizar en el espacio los conflictos ambientales» (Ochoa, 2012). La variable estrella es el territorio, visto no sólo como espacio geográfico sino como un lugar lleno de significados identitarios, donde los actores desarrollan su cotidianidad. El reto de la metodología es el dinamismo y la flexibilidad que debe tener para sistematizar, sin mutilar la esencia de los movimientos-grupos-organizaciones que son contenidos en la matriz.

Sin lugar a dudas, este aporte metodológico es una herramienta para sistematizar y analizar la diversidad de conflictos, sus propuestas alternativas, estrategias y redes que se tejen en el dinamismo de los conflictos y movilizaciones socioambientales. La metodología no sólo permite identificar problemas, conflictos y movimientos socioambientales, sino también actores locales con nombre y apellido, su vinculación o formación de redes, acciones, evolución, estrategias y alternativas, y desde luego facilita el análisis al conjugar diversas variables... todo esto visualizado en un mapa.

La voz de una activista socioambiental se hace presente en el libro para explayar sus reflexiones y vivencias sobre las movilizaciones dadas en la conferencia de Cancún. Lizette Santana hace un llamado a la reflexión acerca de los intereses ocultos que se tejen en las reuniones internacionales lideradas por la Organización de las Naciones Unidas (onu) y el grupo del Banco Mundial. El cambio climático y su preservación se han convertido en un «negocio redondo». Un negocio donde los Estados nación, congregados en estas cum- 
bres, aportan cifras millonarias para mitigar la degradación ambiental, a la par que se ha abierto un nuevo mercado de valores y productos ambientales, donde los capitales siguen ganando a pesar de su contribución negativa al medio ambiente. Deja en claro que a quienes se protege es a los intereses de los capitales privados internacionales y no al medio ambiente.

Regalado Santillán comparte notas que reflexionan sobre la urgencia de pensar en otra epistemología para estudiar y analizar pueblos, culturas, cosmovisiones que no pueden ser comprendidas desde la metodología de carácter cientificista y positivista que buscan «mediciones», cuando en las ciencias sociales tenemos que comprenderlas para poder explicarlas y dar aportes. El mismo autor señala que «aspira a despertar algunas preguntas respecto de la posible y deseable construcción colectiva de otra epistemología; de otra forma de producir conocimiento, una forma diferente de mirar a los sujetos sociales en movimiento, en acción, construyendo autonomía o en resistencia, muchas veces confundida con apatía» (Regalado, 2012). Es claro el reto: ¿cómo descolonizarnos ideológica y académicamente de las corrientes del pensamiento eurocentristas para recrear una epistemología que nos permita comprender no sólo los movimientos sociales que se producen en México y América Latina sino cualquier otra línea de análisis de las ciencias sociales?

Para terminar, Conflictos socioambientales y alternativas de la sociedad civil nos proporciona una amplia gama de estudios realizados desde la agroecología y la ecología política, y desde la investigación participante. Los autores no se limitan a informar y analizar los casos, sino que nos invitan a reflexionar y generar conciencia social, necesaria para trabajar con las personas que se cohesionan y para dar respuesta a sus realidades. La pregunta es: ¿cómo repercuten o influyen este tipo de libros que nacen de las movilizaciones sociales, en el corazón o acción de estos cultivos sociales? Es un reto enorme para las ciencias sociales devolver y dar uso social al conocimiento generado, y no sólo reservarlo para el análisis teórico-metodológico en las ciencias sociales. 


\section{Referencias}

Amın, Samir (2001), «Imperialism and Globalization», Montly Review, volumen 53 , número 2.

Gutiérrez, Esthela y Édgar González (2010), De las teorías del desarrollo al desarrollo sustentable: construcción de un enfoque multidisciplinario, México, Siglo xxi, Universidad Autónoma de Nuevo León.

Harvey, David (2004), El nuevo imperialismo, Madrid, Akal.

Marx, Karl (1980), El capital. Crítica de la economía política, México, Siglo XXI.

Оснод, Heliodoro (2012), «Mapeo de conflictos ambientales y alternativas en Jalisco, aportes para una metodología», en Darcy Tetreault, Heliodoro Ochoa y Eduardo Hernández (coordinadores), Conflictos socioambientales y alternativas de la sociedad civil, Tlaquepaque, ITESO.

Regalado, Jorge (2012), «Notas deshilvanadas sobre otra epistemología», en Darcy Tetreault, Heliodoro Ochoa y Eduardo Hernández (coordinadores), Conflictos socioambientales y alternativas de la sociedad civil, Tlaquepaque, iteso.

Tetreault, Darcy, Heliodoro Ochoa y Eduardo Hernández (2012), «Introducción», en Darcy Tetreault, Heliodoro Ochoa y Eduardo Hernández (coordinadores), Conflictos socioambientales y alternativas de la sociedad civil, Tlaquepaque, IтESO. 